\title{
editorial
}

\section{The end of optimism?}

$\mathrm{T}$ here was a time when many believed that science was the way to a better future, the solution to all of mankind's needs and the secret to understanding ourselves. No more. The recent anniversary of the launch of Sputnik is a reminder of how times have changed. Back in the 1950s and 1960s there was a general optimism and excitement about science, technology and engineering; citizens believed that scientists could free humanity from the constraints of Earth and reach for new frontiers. At the same time, antibiotics and vaccines had apparently freed mankind from the threat of infectious disease and, when President Richard Nixon launched the 'war on cancer', he was certain that he would see it finished within his lifetime.

However, Nixon passed away and cancer is not cured; scientists have had to recognize the difference between research and engineering. Launching a satellite or sending a man to the moon were technological challenges, but they were based on the application of sound knowledge. By contrast, curing cancer requires an understanding of the complexity of cells, which has turned out to be a slow struggle. For a time, society had high expectations of science, but questions about the power of the research machine, its links with industry and the low return on investment began to detract from the optimism of scientific endeavour. The general mood has changed since a man walked on the moon.

Thus, we live in a time when critics challenge the power of the scientific enterprise and when scientists, deprived of optimistic support, have to justify their work on the most elaborate and often exaggerated terms. The scientific and technological breakthroughs that allowed researchers to isolate specific genes and transfer them between organisms could have reversed this scepticism, but, instead of generating applause, it put scientists on the defensive against accusations that they were 'playing God'. Campaigns to stop the newly termed 'recombinant DNA technology' did not succeed in the end, but the seeds of doubt were sown. This narrow victory was followed by the fiasco of introducing genetically modified crops, almost by stealth, which was subsumed into a marketing strategy to change millennia-old agricultural practices for the benefit of a few companies. Not surprisingly, the trust between society and scientists suffered. It should therefore not have come as a surprise when certain parties used the advent of BSE - and even HIV-to claim that science was the cause of these problems, rather than the solution. All of these strands strengthened each other such that, today, much science is widely perceived with scepticism or even fear.

The media still report on the latest breakthroughs in research, but journalists have grown equally cynical about the rosy claims issued in the press releases from companies and universities alike. Indeed, these soundbites contribute to society's growing loss of optimism for research. How many times have we heard that a major breakthrough in the treatment of cancer has been achieved, when in reality a surgeon's skills are still superior to designer chemicals? A clear sign of the lack of optimism is the continued trust in alternative 'natural' cures, and the fact that scientists and politicians need to reiterate constantly the message that research is our best strategy to meet the needs of society.

Of course, as I have pointed out, scientists share some of the blame for exaggerating the social, health or environmental implications of their research (Gannon F (2007) EMBO Rep 8: 1087). But keeping silent until further research and clinical data can provide enough evidence for the efficiency of a new drug or therapy is no longer an option. The funders of research expect a message that there is a positive return on investment-be it public or private-the hosting institute clamours for a higher ranking in research excellence and the researchers need to build their reputation.

Nonetheless, the growing cynicism and pessimism about research is not only inappropriate, it is also against the best interests of society. If we allowed the critics of research to set the agenda, the consequence would be less research, less knowledge and inevitably less dependence on factual evidence generally in all human activities. Moreover, the luddites are unlikely to provide any solutions to the problems for which we dearly need solutions. But if these answers do not come from science, then how will we be able to create a healthier and sustainable society?

As a community, scientists must therefore work hard to counter this creeping cynicism and instill a healthy dose of optimism about what science can do-albeit in a fair and balanced way. We have to do this for ourselves as well as society at large. We have to explain the complexities of the tasks that lie ahead and, at the same time, highlight the genuine successes that scientific research has achieved. We must counter the cheap shots directed against honest and determined scientists, and reign in those who overstate their work and its implications. But more than anything else, we have to stress time and again that rigorous research is the only way to discover the cures and solutions needed for the twenty-first century. This optimistic message must also encourage the younger generation to join the quest for understanding and help to develop the new services and products that come from it. Sputnik was a huge technological and scientific breakthrough; it was a testament to human ingenuity that led all societies to invest more in education and research. Today, that optimism is waning, and we are facing an even bigger and more universal challenge; one that we must meet with optimism for exciting and successful scientific research.

\section{Frank Gannon \\ This Editorial represents the personal views of Frank Gannon and not those of Science Foundation Ireland or the European Molecular Biology Organization.}

doi:10.1038/sj.embor.7401165 